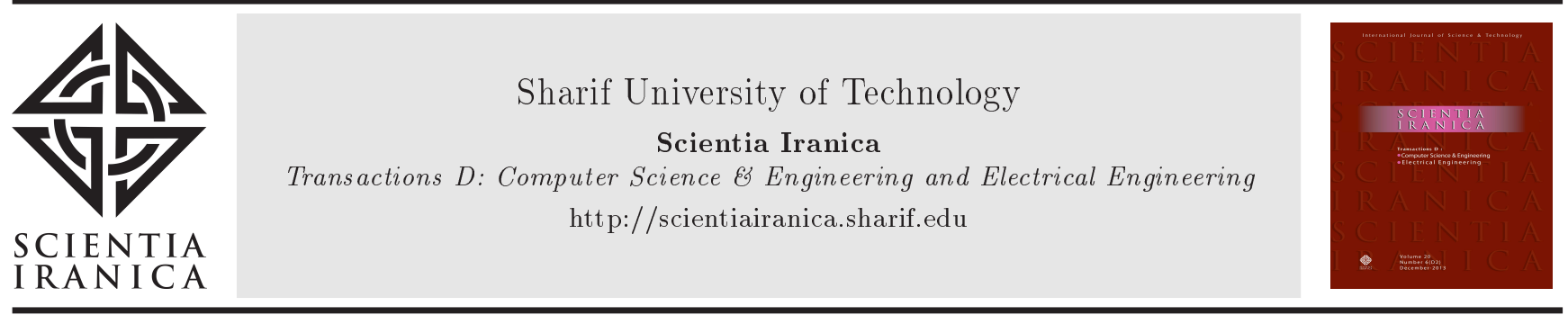

\title{
Honeycomb shaped fractal antenna with dual notch characteristic for UWB applications
}

\author{
U. Keshwala ${ }^{\mathrm{a}, \mathrm{b}}$, K. Ray ${ }^{\mathrm{c}}$, and S. Rawat ${ }^{\mathrm{d}}{ }^{*}$ \\ a. ECE, Amity University Uttar-Pradesh, Noida, 201301, India. \\ b. ECE, ASET, Amity University Rajasthan, Jaipur, 303007, India. \\ c. ASAS, Amity University Rajasthan, Jaipur, 303007, India. \\ d. ECE, Manipal University Jaipur, 303007, India.
}

Received 12 August 2020; received in revised form 11 November 2020; accepted 1 March 2021

\author{
KEYWORDS \\ Ultra-wide band \\ antenna; \\ Honeycomb nest \\ shape fractal antenna; \\ Defected ground \\ structure; \\ Band notch \\ characteristics.
}

\begin{abstract}
This paper presents a feasible way to construct a honeycomb structured microstrip antenna for UWB (Ultra-Wide Band) applications with dual notch characteristics. The antenna is designed based on the concept of the initial stage of honeycomb nest construction and Defected Ground Structure (DGS) with dual notch for UWB applications. The two notches for WiMAX (3.5 GHz center frequency) and WLAN (5.5 GHz center frequency) are introduced by etching two asymmetrical quarter-wavelength slots in the ground. The compact antenna of size $12 \times 20 \mathrm{~mm}^{2}$ with simple geometry achieves very wide bandwidth of $3.1-13.8 \mathrm{GHz}$ (covers UWB and higher frequency band) with dual notch characteristics.
\end{abstract}

(C) 2022 Sharif University of Technology. All rights reserved.

\section{Introduction}

Nature is an exceptionally large and unique laboratory comprising efficient explanations on and solutions to numerous technical and scientific problems. Honeycomb structures inspired by the Mother Nature's bee honeycomb construction process have tremendous potentials and applications in various fields including mechanical engineering, nanofabrication, chemical engineering, architecture, aerospace engineering, biomedicines, and RF (Radio Frequency) and microwave. The ideas and theories taken from nature have inspired many novel designs of antennas for various wireless applications [1-3].

\footnotetext{
*. Corresponding author. Tel.: +919414069888 E-mail addresses: Usha_keshwala30@yahoo.com (U. Keshwala); kanadray00@gmail.com (K. Ray); sanyog.rawat@gmail.com (S.Rawat)
}

The fractal patterns exist around every corner of nature. The fractal structure of honeycomb evolving from natural honeycomb is a tessellation of uniformly distributed double-layer hexagonal shapes. There are mainly two viewpoints on how the shape of honeycomb cells becomes hexagonal. One is that the particular structure is merely the result of physics law. The other point of view suggests that honeybees are skilled engineers that operate under simple rules. With the advent of new technology, the application of honeycomb structure is growing on nano and micro scales. Various micro and nano antennas based on honeycomb structure have been proposed for various applications [4-7].

The wide-band antennas were built with monopoles of various shapes or fractal shapes $[8,9]$. At a particular frequency, the antenna must normally maintain a minimum size, usually in the order of quarter wavelengths. These factors affecting the antenna performance in telecommunication systems have remained restricted for a long time. Fractal 
electromagnetic engineering embodies a comparatively fresh domain of research that amalgamates aspects of fractal geometry with electromagnetics. Research within this stream has lately given rise to a rich category of innovative structures for antennas along with metamaterial rudiments. Fractals are space-filling structures that could be utilized as electromagnetic devices to efficiently accommodate long electrical lengths into tiny areas. Honeycomb is the most suitable fractal shape found in nature for the design of patch antennas [7].

Since FCC (Federal Communication Commission) regulated the frequency range of $3.1-10.6 \mathrm{GHz}$ for the Ultra-Wideband (UWB) applications, much attention has been paid to the growing demand for UWB antennas for the UWB technology [10,11]. For millimeterwave applications, a honeycomb fractal antenna array of size $97 \times 7 \mathrm{~mm}^{2}$ was introduced in [5]. The broad bandwidth of $14.337 \mathrm{GHz}(25.347-39.684 \mathrm{GHz})$ was obtained with $4.15 \mathrm{dBi}$ (single component) and $12.7 \mathrm{dBi}$ (antenna array) gain. For wireless applications, Desai et al. [6] presented a hexagon fractal antenna of bandwidth $1.31-6.81 \mathrm{GHz}$ and a gain of $6.8 \mathrm{dBi}$ and $40 \times 45 \mathrm{~mm}^{2}$ size. This referenced study [7] presented an $80 \times 80 \mathrm{~mm}^{2}$ honeycomb-shaped antenna for $\mathrm{Ku}$ band communication at a frequency of $11.85 \mathrm{GHz}$ with a gain of $8.87 \mathrm{dBi}$. The CPW (Coplanar Waveguide) fed hexagonal fractal antenna of size $39 \times 36.5 \times$ $1.524 \mathrm{~mm}^{3}$ design was proposed for UWB applications [12]. The modeling of the PIN (Positive-IntrinsicNegative) diode RF (Radio Frequency) switch on HFSS (High-Frequency Structure Simulator) was presented for reconfigurable antenna applications [13]. A simple compact-size antenna with the partial ground is added with a frequency reconfigurable property to switch from the ultra-wideband to narrowband mode. In [14], plasmonic mode propagation properties of graphenebased terahertz PCA (Photoconductive Antennas) are studied. Some of the nature-inspired algorithms are applied to antenna optimization $[15,16]$.

In this paper, the honeycomb structure construction is considered for the design of the conducting patch of an antenna. This paper presents a honeycombstructured fractal antenna with dual-band notch rejection characteristics for UWB applications.

\section{Antenna design}

\subsection{Initial antenna design}

The mechanism through which honeybees assemble honeycomb cells in such a particular order is nevertheless an open discussion. When the honeycomb structure is subjected to different loads and stresses, much attention should be paid to the mechanical properties [17]. In this paper, the honeycomb structure is explored for the microstrip antenna design. A critical understanding of the construction principle of the honeycomb structure to design an antenna is important. In order to construct the honeycomb antenna, the focus of attention is the initial structure of the honeycomb. By considering this initial honeycombstructured construct procedure [18], the design of an antenna is initiated, as shown in Figure 1. Figure 1(a) shows the first stage of honeycomb construction, and Figure 1(b) shows the antenna patch using conducting material. The antenna is constructed on the FR-4 substrate of size $20 \times 12 \mathrm{~mm}^{2}$.

As can be observed from the above antenna design, the antenna forms the quarter-wavelength or half-wavelength monopole. The length of the radiating patch is approximately a quarter of the wavelength and the total length $l_{\text {total }}$ is given by:
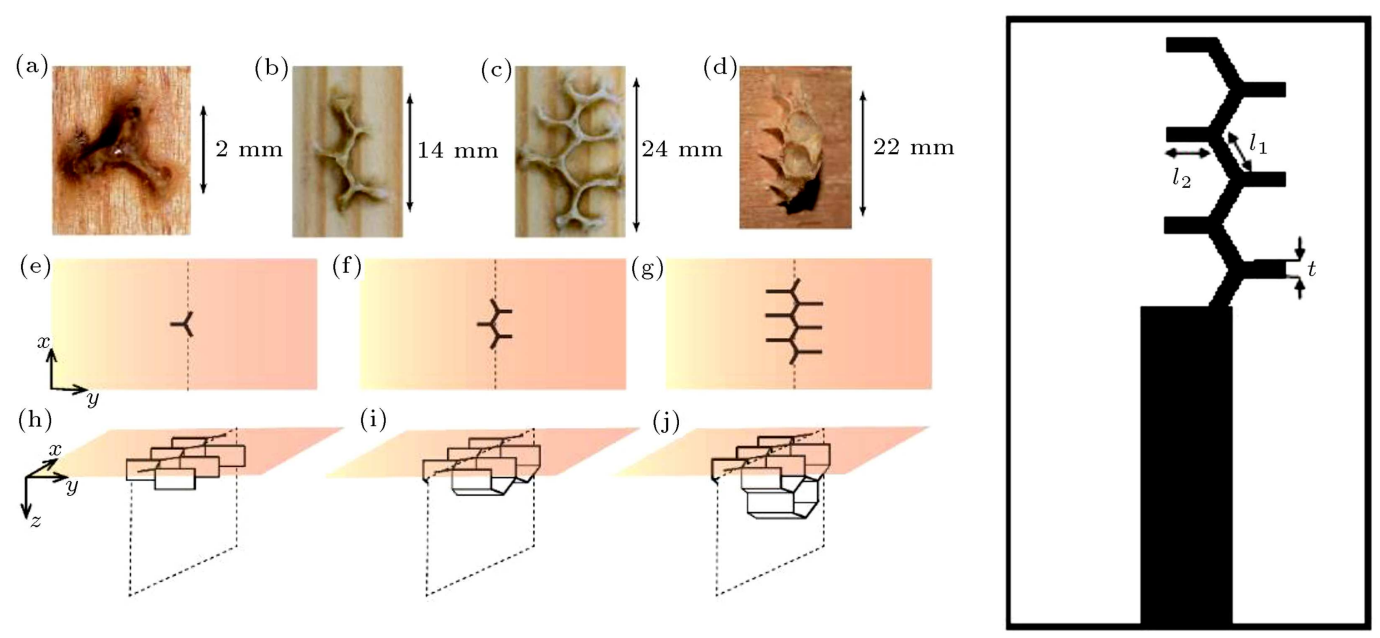

(a)

(b)

Figure 1. (a) Initial stage of honeycomb structure [18]. (b) Initial antenna design. 


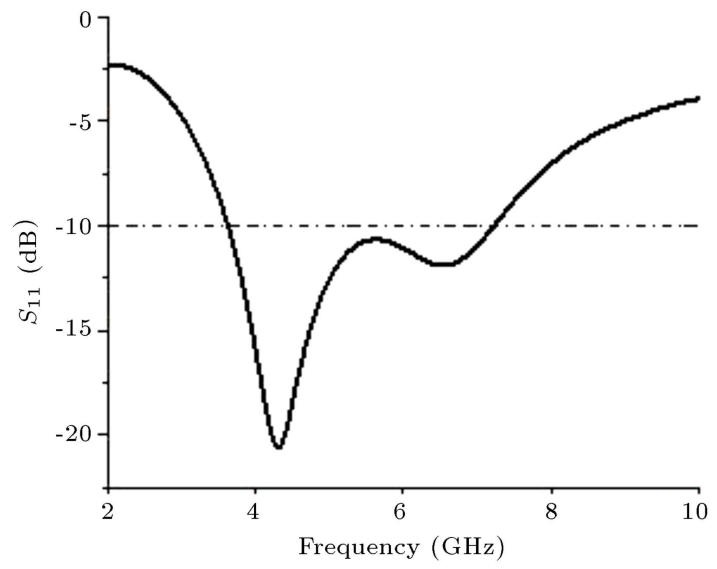

Figure 2. Return loss variation for quarter-wavelength patch.

$$
\begin{aligned}
& l_{\text {total }} \frac{\lambda_{0}}{4}=\frac{\lambda_{r}}{4 \sqrt{\varepsilon_{e f f}}}=\frac{C}{4 f_{r} \sqrt{\varepsilon_{e f f}}}, \\
& \varepsilon_{e f f}=\frac{\varepsilon_{r}+1}{2},
\end{aligned}
$$

where $C$ is the speed of light in the free space, $\lambda_{r}$ the free space wavelength, $\varepsilon_{e f f}$ effective dielectric constant, and $f_{r}$ the resonant frequency of the quarterwavelength monopole [19]. The total patch length $l_{\text {total }}$ for the above design is approximately $10 \mathrm{~mm}$ $\left(l_{1}=1.4 \mathrm{~mm}, l_{2}=2 \mathrm{~mm}\right.$, and $\left.t=0.5 \mathrm{~mm}\right)$. The resonating frequency for the quarter-wavelength monopole of $10 \mathrm{~mm}$ length is $4.4 \mathrm{GHz}$. According to the obtained return loss characteristics shown in Figure 2, the resonating frequency is $4.3 \mathrm{GHz}$ and the obtained bandwidth ranges from 3.6 to $7.2 \mathrm{GHz}(3.6 \mathrm{GHz})$.

The initial design is optimized by the tessellation of the hexagonal fractal shapes in a circular manner and hence, the initial design of quarter wavelength is modified into the honeycomb shape [20], as shown in Figure 3.

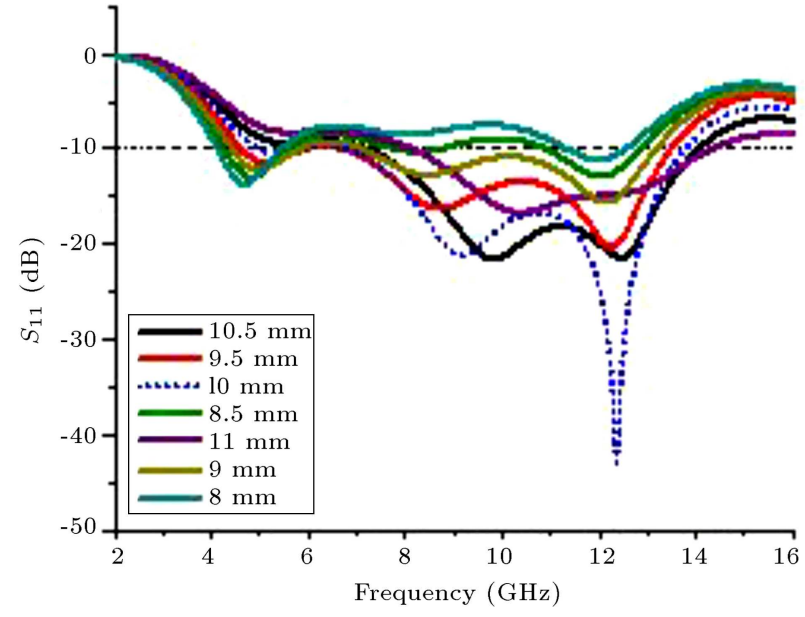

Figure 4. Variation of return loss $\left(S_{11}\right)$ with frequency for different ground sizes.

For a wide bandwidth, the parametric analysis of ground is conducted by changing the ground size. Figure 4 shows the variation of return loss $\left(S_{11}\right)$ with frequency for different ground sizes. By observing the obtained graphs closely, it can be noted that the results are optimum when the ground length $L_{1}$ is $10 \mathrm{~mm}$. With a ground length of $10 \mathrm{~mm}$, the bandwidth ranges from 6.749 to $13.743 \mathrm{GHz}$, which covers the part of UWB and Ku-band.

To further enhance the bandwidth in the UWB range, the ground is modified into Defected Ground Structure (DGS) by inserting a triangular slot in the upper part of the partial ground plane [21]. In addition to the triangular slot, hexagonal patches are introduced in the patch, as shown in Figure 5. Incorporation of hexagon shapes into the patch and triangular slot in the partial ground further improves the bandwidth of an antenna by changing the current distribution and electrical path lengths. The electrical path length for

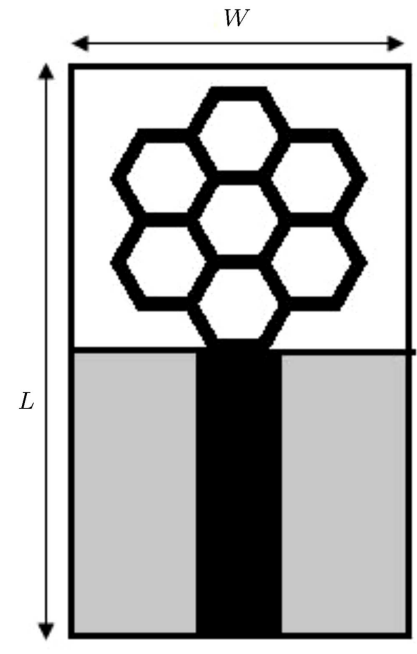

(a)

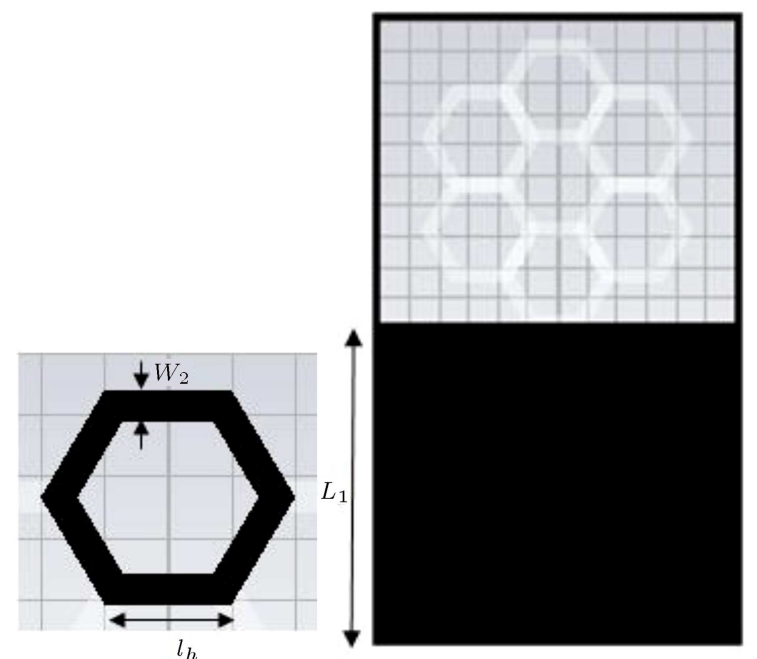

(b) (c)

Figure 3. (a) Honeycomb shaped fractal antenna, (b) single hexagonal fractal, and (c) back view of antenna. 

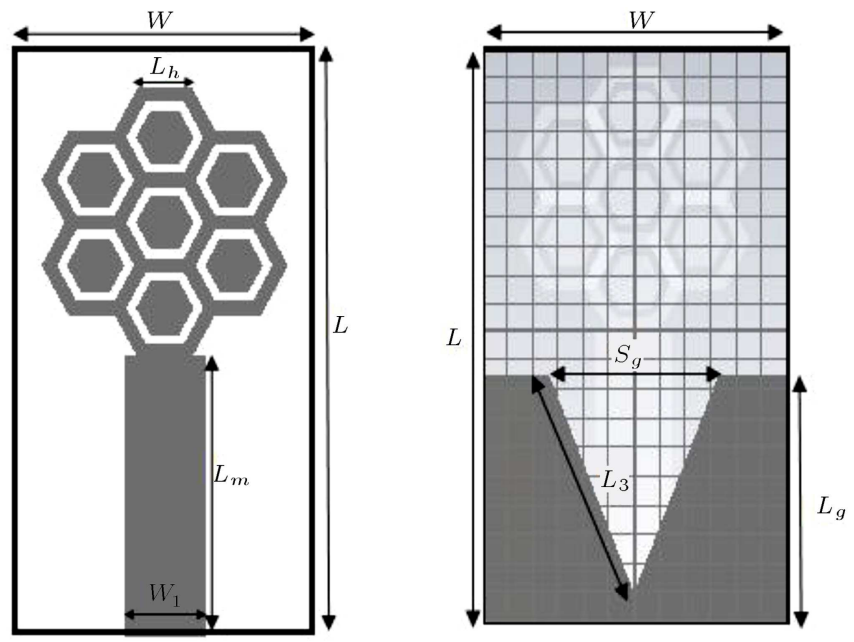

(a)
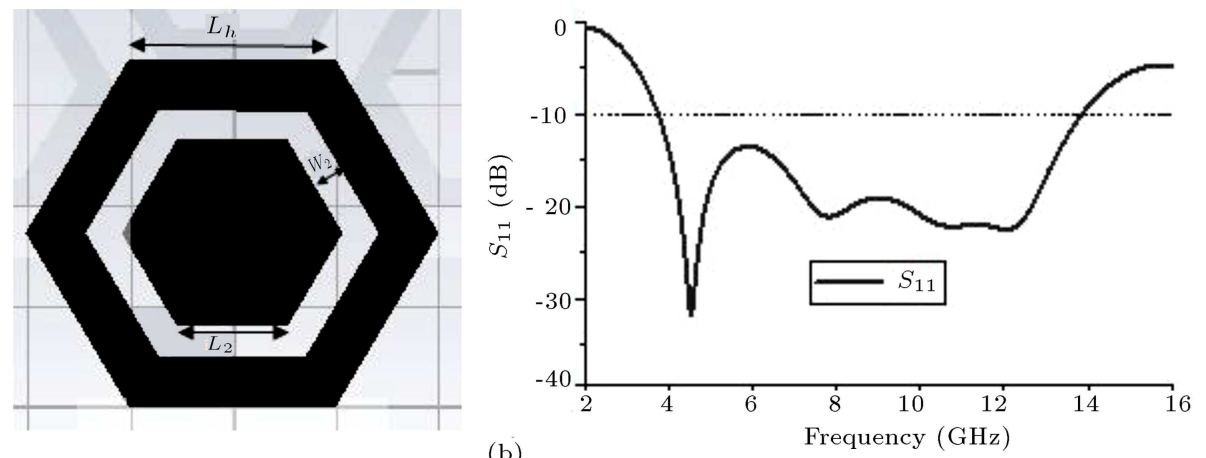

(b)

Figure 5. (a) Honeycomb structure filled with hexagonal front view (left panel) patches and with DGS (right panel). (b) Single hexagonal fractal with filled patch (left panel) and return loss variation (right panel).

the ground without a triangular slot is $L_{g}+W(8.5$ $\mathrm{mm}+12 \mathrm{~mm}=20.5 \mathrm{~mm})$. The electrical path length is changed into $L_{g}+l_{3}+l_{3}+\left(W-S_{q}\right)(8.5 \mathrm{~mm}+8.2 \mathrm{~mm}$ $+8.2 \mathrm{~mm}+(12 \mathrm{~mm}-6.67 \mathrm{~mm})=30.23 \mathrm{~mm})$. The impedance bandwidth is highly enhanced from 6.74913.743 GHz to $3.74-13.85 \mathrm{GHz}$, as shown in Figure 5 .

\subsection{Dual-band notch antenna}

After obtaining wide bandwidth, the next step is to address the issue of interference in the coexisting microwave systems by introducing slots in the ground, as shown in Figure 6 . The first notch for WiMAX $(3.25-3.85 \mathrm{GHz})$ is introduced by etching the quarterwavelength $\left(\lambda_{g} / 4\right)$ slot of length $10.5 \mathrm{~mm}$. Here, $\lambda_{g}$ is the guided wavelength for the corresponding notch-band center frequency. As depicted in Figure 7, slot 1 introduces a notch for WiMAX. Similarly, the WLAN notch is introduced at the center frequency of $5.5 \mathrm{GHz}$ by etching a quarter-wavelength inverted L-shaped slot in the ground, as shown in Figure 8. The inverted $\mathrm{L}$ shape is chosen to accommodate the quarter-wavelength slot in a very-compact-size DGS. The length of the quarter-wavelength slot is calculated, as given in Eq. (1) [19,22].

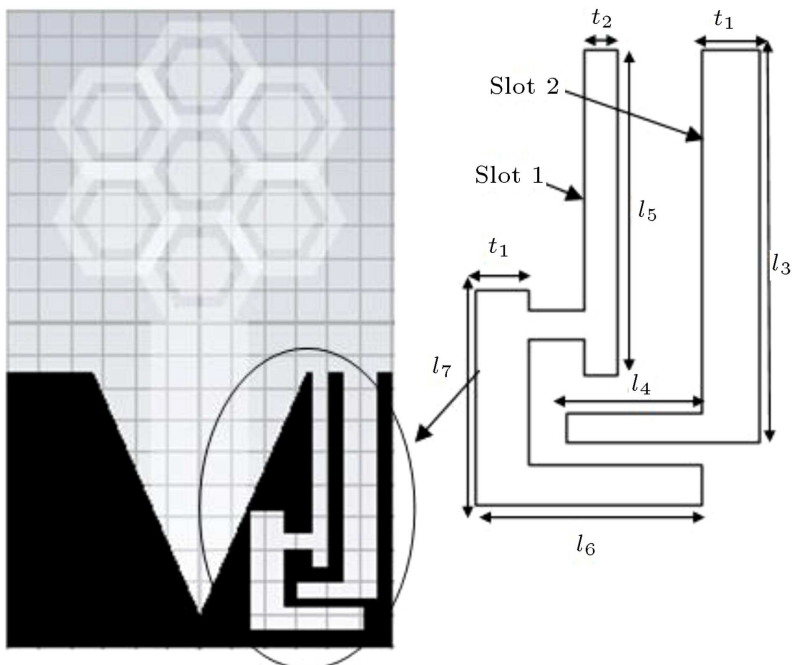

Figure 6. Quarter-wavelength slots in DGS for band notch characteristics (proposed antenna design) and enlarged view of ground slots.

\section{Results and discussions}

The effective lengths of the two slots (slots 1 and 2) are $10.5 \mathrm{~mm}$ and $7.75 \mathrm{~mm}$, respectively. Here, the 


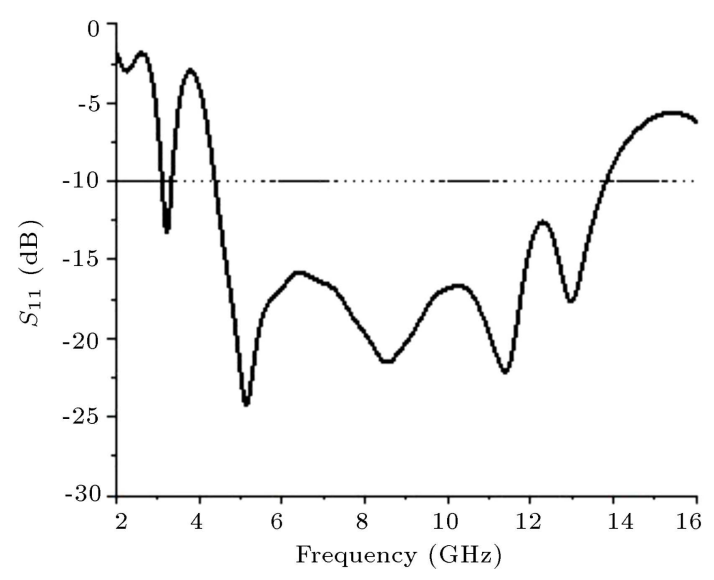

Figure 7. WiMAX notch by quarter-wavelength slot.

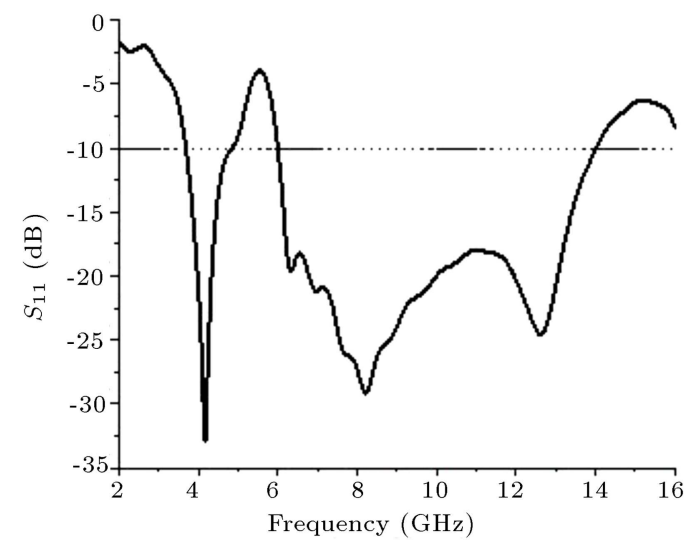

Figure 8. WLAN notch by qutaer-wavelength slot.

effective lengths of slots are considered $\lambda_{g} / 4$ instead of $\lambda_{g} / 2$ to accommodate the slots in very compact size ground and to reduce the design complexity. When both slots are added together, the obtained return loss, VSWR (Voltage Standing Wave Ratio), gain characteristics, and efficiency variations are displayed in Figure 9. The band rejection notches are created at the center frequencies of $3.5 \mathrm{GHz}$ and $5.5 \mathrm{GHz}$ to mitigate the issue of interference. The gain is reduced to $-2.7 \mathrm{dBi}$ and $-4.75 \mathrm{dBi}$ at the WiMAX and WLAN notches, respectively, and a maximum gain of $2.6 \mathrm{dBi}$ is acquired at $11 \mathrm{GHz}$, as shown in Figure 9(b). Due to the introduction of band notches at $3.5 \mathrm{GHz}$ and $5.5 \mathrm{GHz}$, the gain is reduced at these two frequencies. In addition, at the reaming frequency band, the gain variation is positive and above $0 \mathrm{dBi}$. The efficiency of an antenna is reduced at band notch frequencies, as shown in Figure 9(c). The optimized antenna parameters are shown in Table 1.

To get an insight into antenna characteristics, the surface current distributions and normalized radiation pattern are shown in Figures 10 and 11, respectively, at resonating frequencies. Figure 10 (b) shows the surface current distribution at band notch frequencies for WLAN and WiMAX. The current is mainly distributed

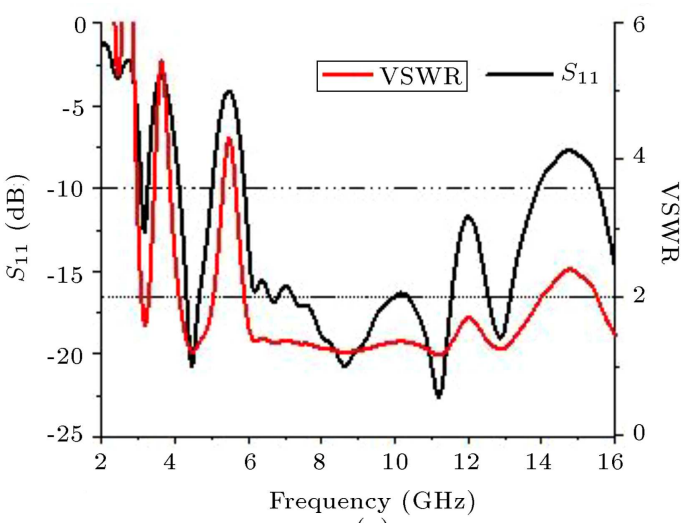

(a)

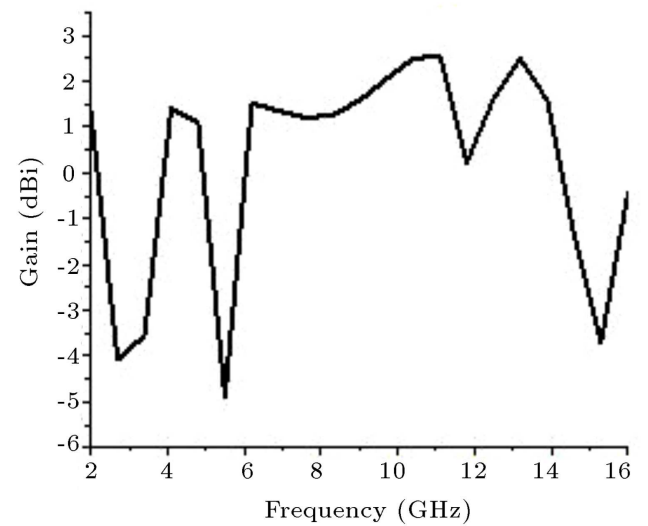

(b)

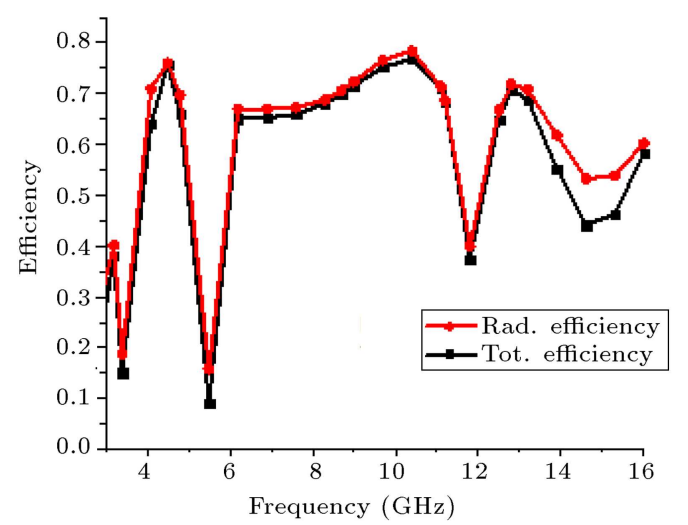

(c)

Figure 9. (a) Return loss and VSWR variation with frequency, (b) gain variation with different frequency, and (c) efficiency variation with frequency.

in slots 1 and 2 and is responsible for the current disturbance and, thus, for the notch creation. The current flows around the periphery of the L-shaped slots, acting, in turn, as a resonator and preventing signal propagation. As can be noted from the current distributions shown at notch band frequencies, at a frequency of $3.5 \mathrm{GHz}$, maximum current is distributed around $3.5 \mathrm{GHz}$ and it plays an essential role in the creation of WiMAX band notch. Moreover, the maximum current is flowing at the periphery of slot 2, resulting in a band notch for the WLAN at $5.5 \mathrm{GHz}$. At 


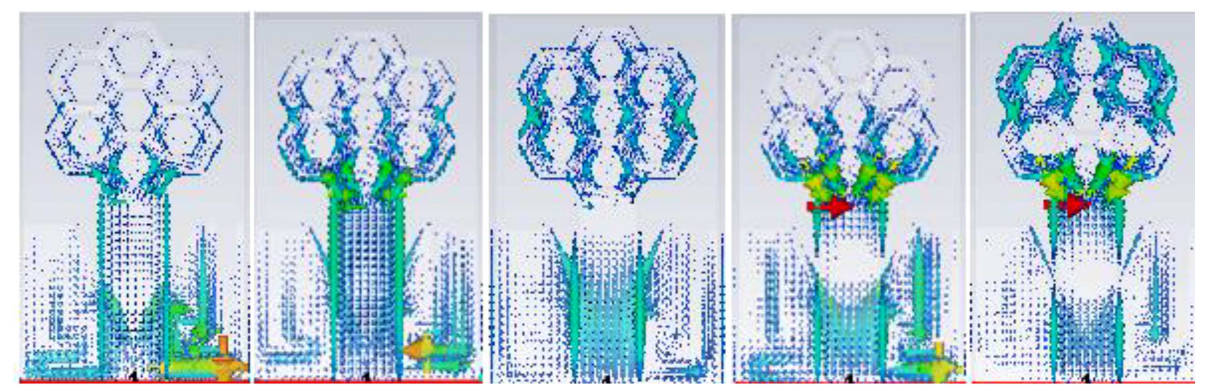

(a)
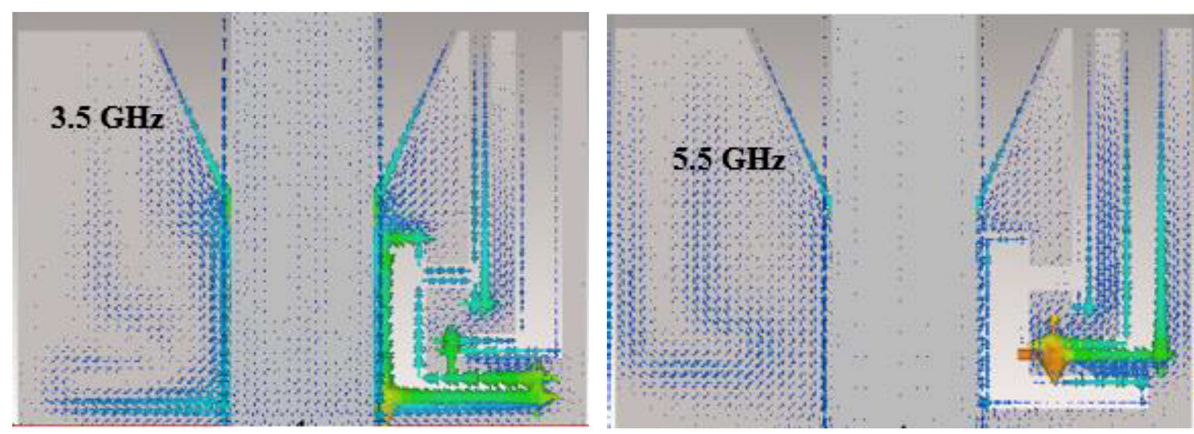

(b)

Figure 10. (a) Surface current distributions at resonating frequencies (3.2, 4.5, 8.7, 11.2, and 12.8 GHz). (b) Surface current distribution in slots at band notch frequencies.

Table 1. Optimized parameters of an antenna.

\begin{tabular}{cccc}
\hline Parameters & $\begin{array}{c}\text { Value } \\
(\mathbf{m m})\end{array}$ & Parameters & $\begin{array}{c}\text { Value } \\
(\mathbf{m m})\end{array}$ \\
\hline$L$ & 20 & $L_{g}$ & 8.5 \\
$W$ & 12 & $S_{g}$ & 6.67 \\
$W 1$ & 3 & $l_{3}$ & 8.2 \\
$L_{1}$ & 10 & $l_{h}$ & 2 \\
$W_{2}$ & 0.3 & $L_{2}$ & 1 \\
$W_{3}$ & 0.5 & $l_{1}$ & 1.4 \\
$t$ & 0.5 & $l_{2}$ & 2 \\
$l_{4}$ & 1.5 & $l_{5}$ & 6 \\
$l_{6}$ & 3.5 & $l_{7}$ & 3.7 \\
\hline
\end{tabular}

higher frequencies, the current is flowing in the patch and responsible for the high frequency resonance.

In thermal equilibrium considering the collective effects of absorption, reflection, and emission in the case of practical materials, the universality of cavity radiation collapses. Radiation inside the cavity depends on the walls, external temperature, and frequency of observation. Thus, the frequency in a perfectly reflecting or arbitrary cavity may differ from that emitted from the ideal case. Emitted radiation pattern inside the considered hexagonal honeycomb cavity follows the back-and-forth wave propagation that depends on the honeycomb cavity wall [23]. Cavity radiation is detached from the nature of the cavity wall and some other external factors like temperature and frequency of observation if cavity walls are of symmetrical shape or plane nature. The contained radiation inside the cavity has the same radiation nature [24]. Observed simulated results of EM wave patterns at resonant frequencies, as shown in Figure 11, illustrate that the emitted radiation patterns are not symmetrically distributed in the hexagonal-shape cavity and they are dependent on the cavity wall of the mimicked honeycomb. Kirchhoff's law in terms of radiated emissive power $(E)$ and absorptivity $(a)$ is given as [25].

$$
E=a \cdot f(T, \nu) \text {. }
$$

We know that the sum of emissivity $(\varepsilon)$ and reflectivity $(k)$ is always equal to 1 for all materials.

$$
\varepsilon+k=1 \text {. }
$$

However, this rule is also the validation of emissivity $\varepsilon$ and absorptivity $a[26,27]$. Thus, we have:

$$
a+k=1
$$

or

$$
\begin{aligned}
& a=1-k, \\
& E=(1-k) \cdot f(T, \nu) .
\end{aligned}
$$

This equation contains reflectivity of cavity material that totally depends on the nature of the cavity's wall. 

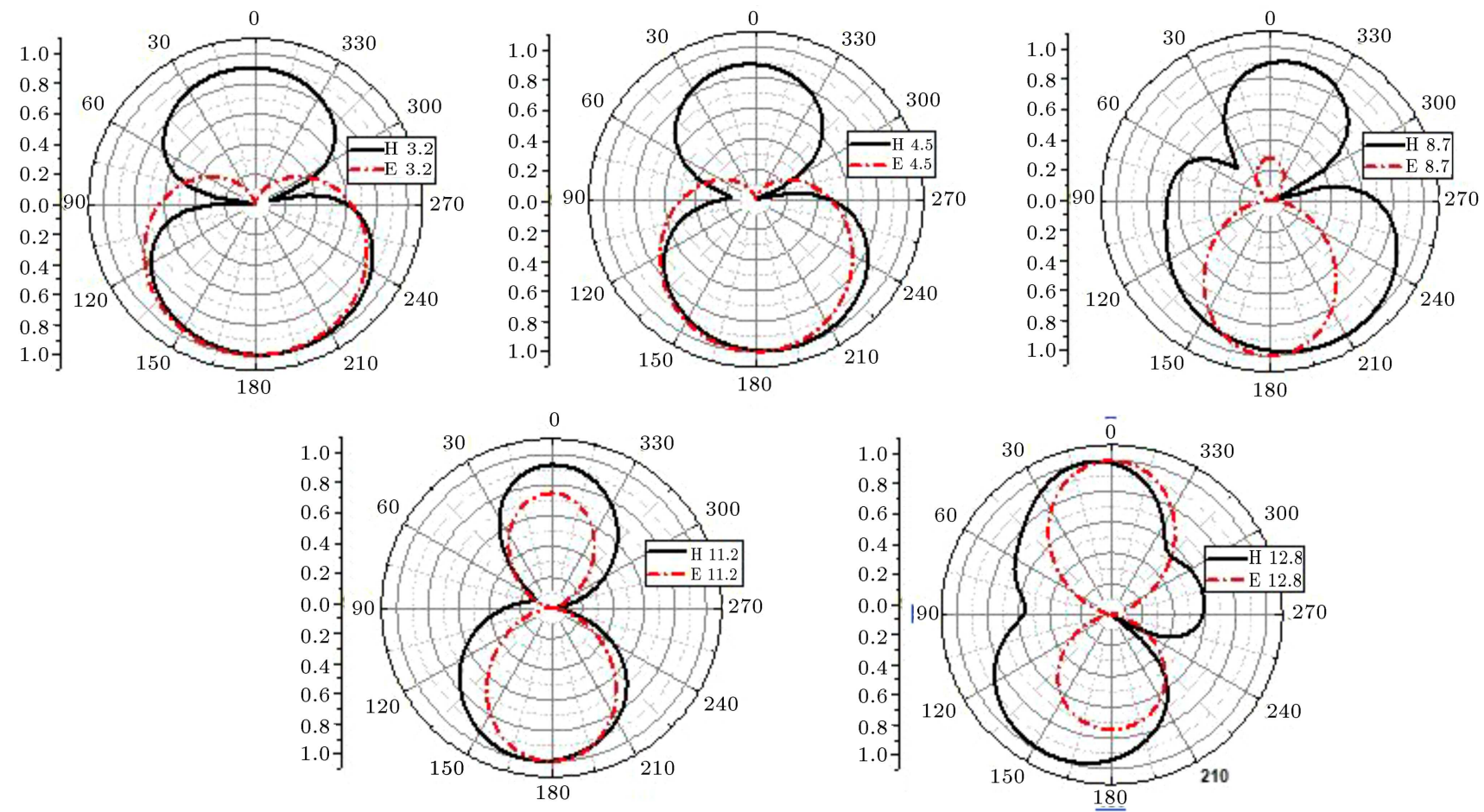

Figure 11. Radiation pattern at resonating frequencies $(3.2,4.5,8.7,11.2$, and $12.8 \mathrm{GHz})$.

Table 2. Comparisons of the proposed work with the reported antenna.

\begin{tabular}{lclc}
\hline Reference & $\begin{array}{c}\text { Size of antenna } \\
\text { (in } \mathbf{~ m m}^{2} \text { ) }\end{array}$ & BW & Gain \\
\hline Ullah et al. $2017[5]$ & $97 \times 7$ & $14.337 \mathrm{GHz}(25.347-39.684 \mathrm{GHz})$ & $4.15 \mathrm{dBi}($ single antenna) \\
Desai et al. $2018[6]$ & $40 \times 45$ & $(1.31-6.81 \mathrm{GHz})$ & $6.8 \mathrm{dBi}$ \\
Bhatoa et al. $2016[7]$ & $80 \times 80$ & $11.85 \mathrm{GHz}(\mathrm{Single}$ frequency) & $8.87 \mathrm{dBi}$ \\
Aissaoui et al. $2016[12]$ & $39 \times 36.5$ & $(3.1-13.67 \mathrm{GHz}) 10.57 \mathrm{GHz}$ & Not given \\
Proposed design & $\mathbf{2 0} \times \mathbf{1 2}$ & $\mathbf{1 0 . 7 0} \mathbf{~ G H z ~ ( 3 . 1 - 1 3 . 8 0 ~ G H z )}$ with dual notch & $\mathbf{2 . 6} \mathbf{~ d B i}$ \\
\hline
\end{tabular}

Through Eq. (3), we can calculate the total emissive and absorptive power for the proposed geometry.

The simple geometry and compact size of antenna have achieved dual notch characteristics in addition to the very wide bandwidth of $10.7 \mathrm{GHz}(3.1-13.8 \mathrm{GHz})$. The comparison between the proposed design and the reported work is shown in Table 2 .

\section{Conclusion}

The compact honeycomb-shaped fractal antenna based on the concept of the initial stage of honeycomb nest construction with dual notch characteristics was presented for Ultra-Wideband (UWB) applications. The antenna obtained very wide bandwidth from 3.1 to $13.8 \mathrm{GHz}$ with WiMAX and WLAN rejection notches at $3.5 \mathrm{GHz}$ and $5.5 \mathrm{GHz}$, respectively. Stable radiation pattern and notch band characteristic make an antenna suitable for Ultra-Wide band (UWB) application with high immunity from the existing interference.

\section{References}

1. Keshwala, U., Rawat, S., and Ray, K. "Nature inspired dual band sneezewort plant growth pattern shaped antenna", Proceedings of 2017 Asia Pacific Microwave Conf., Kuala Lumpur, Malaysia, pp. 580-583 (2017). 10.1109/apmc.2017.8251512

2. Singh, P., Ray, K., and Rawat, S. "Analysis of sun flower shaped monopole antenna", Wireless Pers Commun, 104(3), pp. 881-894 (2018). DOI: org/10.1007/s11277-018-6056-z

3. Singh, P, Ocampo, M., Lugo, J., et al. "Fractal and periodical biological antennas: Hidden topologies in DNA, wasps and retina in the eye", Soft Computing Applications, Springer Singapore, pp. 113-130 (2018).

4. Nakano, H., Tajima, S., Nakayama, K., et al. "Numerical analysis of honeycomb antennas with an electromagnetic coupling feed system", Proc. Inst. Elec. Eng. Microw. Antennas Propagation, 145(1), pp. 99103 (1998). DOI: 10 1049/ip-map:19981451

5. Ulla, H., Tahir, F.A., and Khan, M.U. "A honeycomb- 
shaped planar monopole antenna for broadband millimeter-wave applications", 11th European Conference on Antennas and Propagation (EUCAP), Paris, France, pp. 3094-3097 (2017).

DOI: 10-23919/EuCAP-2017-7928856

6. Desai, A., Upadhyaya, T., Patel, R., et al. "Wideband high gain fractal antenna for wireless applications", Progress In Electromagnetics Research Letters, 74, pp. 125-130 (2018). DOI: 10 2528/PIERL18011504

7. Bhatoa, R., Saini, S.S., Sharma, S., et al. "Novel high gain honeycomb shaped slotted ground microstrip patch antenna design for broadcasting fixed satellite mobile satellite and downlink frequency applications", 2016 International Conference on Global Trends in Signal Processing, Information Computing and Communication (ICGTSPICC), Jalgaon, pp. 348352 (2016).

DOI: 10.1109/ICGTSPICC.2016.7955326

8. Rajeshkumar, V. and Raghavan, S. "Bandwidth enhanced compact fractal antenna for UWB applications with 5-6 GHz band rejection", Microw Opt Techn Let., 57(3), pp. 2496-2500 (2015).

https://doi org/10 1002/mop 28913

9. Shahu, B.L., Pal, S., and Chattoraj, N. "Design of super wideband Hexagonal-shaped fractal Antenna with Triangular slot", Microw Opt Techn Let., 57(7), pp. 1659-1662 (2015).

https://doi org/10 1002/mop 29184.

10. The Federal Communications Commission (FCC), Revision of Part 15 of the Commission's Rules Regarding Ultra-Wideband Transmission Systems; First Report and Order FCC 02-48 22 April 2002; The Federal Communications Commission: Washington DC USA (2002).

11. The Federal Communications Commission (FCC), Revision of Part 15 of the Commission's Rules Regarding Ultra Wideband Transmission Systems; First Report and Order FCC 03-33 20 September 2007; The Federal Communications Commission: Washington DC USA (2007).

12. Aissaoui, D., Abdelghani, L.M., Boukli-Hacen, N., et al. "CPW-fed UWB hexagonal shaped antenna with additional fractal elements", Microw Opt Techn Lett., 58(10), pp. 2370-2374 (2016). https://doi-org/101002/mop30053

13. Kumar, J., Basu, B., and Talukdar, F.A. "Modeling of a PIN diode RF switch for reconfigurable antenna application", Scientia Iranica, 26(3), pp. 1714-1723 (2019).

DOI: $10.24200 /$ sci.2018.20110

14. Zolfagharloo Koohi, M. and Neshat, M. "Evaluation of graphene-based terahertz photoconductive antenna", Scientia Iranica, 22(3), pp. 1299-1305 (2015).

15. Ram, G., Mandal, D., Kar, R., et al. "Opposition based gravitational search algorithm for synthesis circular and concentric circular antenna arrays", Scientia Iranica, 22(6), pp. 2457-2471 (2015).
16. Ram, G., Mandal, D., Prasad Ghoshal, S., et al. "Optimization of radiation characteristic of time modulated circular geometry using DEWM", Scientia Iranica, 25(3), pp. 1571-1581 (2018).

DOI: $10.24200 /$ sci.2017.4372

17. Foo, C.C., Chai, G.B., and Seah, L.K. "Mechanical properties of Nomex material and Nomex honeycomb structure", Compos. Struct., 80, pp. 588-594 (2007). DOI: $10.1016 /$ j.compstruct.2006.07.010

18. Narumi, T., Uemichi, K., Honda, H., et al. "Selforganization at the first stage of honeycomb construction: analysis of an attachment-excavation model", PLoS ONE, 13(10), e0205353 (2018).

19. Jhajharia, T., Tiwari, V., Yadav, D., et al. "Wideband circularly polarized antenna with an asymmetric meandered-shaped monopole and defected ground structure for wireless communication", IET Microw Antennas P., 12(9), pp. 1554-1558 (2018).

DOI: 10 1049/iet-map 20180092

20. Keshwala, U., Rawat, S., and Ray, K. "Honeycomb shaped fractal antenna with defected ground structure for UWB applications", International Conference on Signal Processing and Integrated Networks (SPIN), Noida, India, pp. 341-345 (2019).

21. Keshwala, U., Rawat, S., Ray, K., et al. "Compact circular monopole antenna with band notch characteristics for UWB applications", 2018 5th International Conference on Signal Processing and Integrated Networks (SPIN), Noida, pp. 312-315 (2018).

DOI:10.1109/SPIN.2018.8474173

22. Mewara, H.S., Deegwal J.K., and Sharma M.M. "A printed Ultra-wideband monopole antenna with triple band notch characteristics", In: Janyani V., Singh G., Tiwari M., d'Alessandro A. (Eds), Optical and Wireless Technologies. Lecture Notes in Electrical Engineering, 546, Springer, Singapore, pp. 243-251 (2020). https://doi.org/10.1007/978-981-13-6159-3_26

23. Planck, M., The Theory of Heat Radiation, P Blakiston's Son \& Co., Dover. Philadelphia PA (1900).

24. Robitaille, P.M. "On the equation which governs cavity radiation", Progress in Physics, 10(2), pp. 126-127 (2014).

25. Robitaille, P.M. "Blackbody radiation and the loss of universality implications for Planck's formulation and Boltzmann's constant", Progress in Physics, 4, pp. 1416 (2009).

26. Robitaille, P.M. "A critical analysis of universality and Kirchhoff's law: A return to Stewart's law of thermal emission", Progress in Physics, 3, pp. 30-33 (2008).

27. Stewart, B. "An account of some experiments on radiant heat involving an extension of Prevost's theory of exchanges", Trans. Royal Soc. Edinburgh, 22(1), pp. 1-20 (1861). DOI: https://doi org/10 $1017 /$ S0080456800031288 


\section{Biographies}

Ushaben Keshwala is presently working as an Assistant Professor at the Electronics and Communication Engineering Department, Amity University Uttar Pradesh, India. She graduated with Bachelor of Engineering (BE) degree in Electronics and Communication from G.H. Patel College of Engineering and Technology, V.V. Nagar, Gujarat, India in 2007. She did her MTech degree in the Electronics and Communication Engineering from Amity University Uttar Pradesh, India in 2013. She is pursuing PhD degree in the research area of planar antennas for wireless and satellite communication systems. She has published more than 10 research papers in peerreviewed International Journals, Book series, and IEEE conferences. Her current research interests include nature-inspired antennas and pseudo random number generation for communication systems.

Kanad Ray (Senior Member, IEEE) received the MSc degree in Physics from Calcutta University and the $\mathrm{PhD}$ degree in the same field from Jadavpur University, West Bengal, India. He has been a Professor of Physics and Electronics and Communication and is currently working as the Head of the Department of Physics, Amity School of Applied Sciences, Amity University Rajasthan (AUR), Jaipur, India. His current research areas of interest include cognition, communication, electromagnetic field theory, antenna and wave propagation, microwave, computational biology, and applied physics. He has been serving as an Editor for various Springer book series. He was an Associate Editor of the Journal of Integrative Neuroscience (The Netherlands: IOS Press).

Sanyog Rawat is presently affiliated with Electronics and Communication Engineering Department, Manipal University Jaipur. He has been into teaching and research for more than 16 years. He graduated with Bachelor of Engineering (BE) in Electronics and Communication, Master of Technology (MTech) in Microwave Engineering, and $\mathrm{PhD}$ in the field of Planar Antennas. He has published more than 80 research papers in peer-reviewed International Journals, Book series, and IEEE conferences. He has supervised nearly 30 MTech Dissertations and $05 \mathrm{PhDs}$ and guiding 06 $\mathrm{PhD}$ scholars. He has organized several workshops, seminars, and national and international conferences. He has served as a member in the editorial board of various national and international Journals. His current research interests include reconfigurable $\mathrm{RF}$ printed circuits and passive and active microwave integrated circuits. He has visited countries like Japan, Thailand, Malaysia, UAE, and Indonesia for academic and research work. He is also a member of several academic and professional bodies, i.e., Senior Member IEEE, Life Member IE, and ISLE. 